\title{
Meningococcal purpura fulminans and severe myocarditis with clinical meningitis but no meningeal inflammation: a case report
}

Mehdi Hage-Sleiman ${ }^{1}$, Nicolas Derre ${ }^{2}$, Charlotte Verdet ${ }^{3}$, Gilles Pialoux ${ }^{4}$, Olivier Gaudin ${ }^{5}$, Patricia Senet ${ }^{6}$, Muriel Fartoukh ${ }^{2,7}$, Mathieu Boissan ${ }^{1,7,8}$ and Marc Garnier $2,7,9^{*}$ (D)

\begin{abstract}
Background: During fulminant meningococcal septicaemia, meningococci are often observed in the cerebrospinal fluid (CSF) although the patients have frequently no meningeal symptoms. Meningococcal meningitis, by contrast, usually features clinical meningeal signs and biochemical markers of inflammation with elevated white blood cell count (pleiocytosis) in the CSF. Cases of typical symptomatic meningitis without these biochemical features are uncommon in adults.

Case presentation: A 21-year-old male presented with meningococcal purpura fulminans and disseminated intravascular coagulation (DIC) associated with multiple organ dysfunction syndrome requiring hospitalization in the Intensive Care Unit. Despite typical meningeal clinical signs, lumbar puncture showed no pleiocytosis, normal glycorachia and normal proteinorachia, whereas the lactate concentration in the CSF was high (5.8 mmol/L). CSF culture showed a high inoculum of serogroup $\mathrm{C}$ meningococci. On day 2 , after initial improvement, a recurrence of hypotension led to the diagnosis of acute meningococcal myocarditis, which evolved favourably within a week. During the hospitalization, distal ischemic and necrotic lesions were observed, predominantly on the fingertips, which were treated with local and systemic vasodilators.

Conclusions: We report a rare case of adult meningococcal disease characterized by an intermediate form of meningitis between purulent meningitis and meningeal inoculation from fulminant meningococcal septicaemia, without classical signs of biological inflammation. It highlights the diagnostic value of CSF lactate, which may warrant administration of a meningeal dosing regimen of beta-lactam antibiotics. This case also demonstrates the potential severity of meningococcal myocarditis; we discuss its pathophysiology, which is distinct from other sepsisrelated cardiomyopathies. Finally, the observed effects of vasodilators on the meningococcal skin ischemia in this case encourages future studies to assess their efficacy in DIC-associated necrosis.
\end{abstract}

Keywords: Meningococcal disease, Purpura fulminans, Meningitis, Neisseria meningitidis, Myocarditis, lloprost, Inflammation, Cerebrospinal fluid

\footnotetext{
* Correspondence: marc.garnier@aphp.fr

${ }^{2}$ Assistance Publique-Hôpitaux de Paris (APHP), Tenon University Hospital,

Medico-Surgical Intensive Care Unit, 4 Rue de la Chine, Paris 75020, France

${ }^{7}$ Sorbonne University School of Medicine, Paris VI, Paris, France

Full list of author information is available at the end of the article
}

(c) The Author(s). 2019 Open Access This article is distributed under the terms of the Creative Commons Attribution 4.0 International License (http://creativecommons.org/licenses/by/4.0/), which permits unrestricted use, distribution, and reproduction in any medium, provided you give appropriate credit to the original author(s) and the source, provide a link to the Creative Commons license, and indicate if changes were made. The Creative Commons Public Domain Dedication waiver (http://creativecommons.org/publicdomain/zero/1.0/) applies to the data made available in this article, unless otherwise stated. 


\section{Background}

Meningococcal disease encompasses several infectious syndromes. Despite the presence of Neisseria meningitidis in the cerebrospinal fluid (CSF) in both meningococcal meningitis and meningococcal septicaemia, these two diseases have distinct clinical presentations due to differences in their pathophysiology; notably, the compartmentalization of the bacterial injury and the inflammatory response [1-3]. Meningococcal meningitis is similar to other forms of acute purulent meningitis, with high $N$. meningitis inoculum in the CSF causing meningeal inflammation and typical clinical signs of meningitis [1-3]. By contrast, in fulminant meningococcal septicaemia, $N$. meningitis multiplies very quickly in the blood, causing extensive endotoxemia and, in the most severe forms, shock and multiple organ dysfunction syndrome $[2,3]$. In this latter form, meningococcemia may be responsible for haematogenous inoculation of the CSF, which leads, in the great majority of cases, to a low level $N$. meningitis meningeal inoculum, which neither triggers significant meningeal pleiocytosis nor causes clinical signs of meningitis [2]. Meningococcemia, classically, may also be responsible for pericardial infection, arthritis, pneumonia, conjunctivitis, panophtalmitis, and infections of the genito-urinary tract $[1,2]$.

We report here a case of meningococcemia with purpura fulminans, septic shock and clinically symptomatic meningitis, yet with no sign of CSF inflammation, associated with acute severe myocarditis.

\section{Case presentation}

A 21-year-old male, who previously suffered only from intermittent asthma, was admitted to the emergency room in March 2018 with a one-day history of headache, nausea, sore throat, and generalised muscle ache. An initial consultation with the family physician had diagnosed influenza but shivers, photophobia, and testicular pain appeared $24 \mathrm{~h}$ later. Subsequent physical examination found new purpuric lesions on the trunk and upper limbs (Fig. 1) leading to admission to hospital.

At admission, the patient's blood pressure was 121/47 $\mathrm{mmHg}$, heart rate was $116 \mathrm{bpm}$, oxygen saturation was $94 \%$ in room air, and his temperature was $38.4^{\circ} \mathrm{C}$. He was slightly drowsy with a Coma Glasgow Scale score of 13, with left parietal headache, nausea and neck stiffness. Cardiovascular, pulmonary and abdominal examination was normal. Laboratory analysis of blood samples revealed high levels of C-reactive protein $(106 \mathrm{mg} / \mathrm{L})$, hyperleukocytosis $\left(24 \times 10^{9}\right.$ white blood cells/L, of which $94 \%$ were neutrophils), and acute non-obstructive renal failure $(3.46 \mathrm{mg} / \mathrm{dL}$ serum creatinine, corresponding to creatinine clearance of $24 \mathrm{~mL} / \mathrm{min}$ ).

Blood cultures were taken and a lumbar puncture was performed, followed immediately by intravenous (IV) administration of $2 \mathrm{~g}$ cefotaxime. The CSF was crystal clear and no hyper-pressure was observed upon puncture of the dura mater. Biochemical analysis of the CSF revealed normal glycorrachia $(3.0 \mathrm{mmol} / \mathrm{L}$, with $4.8 \mathrm{mmol} / \mathrm{L}$ glycaemia), normal protein content $(0.22 \mathrm{~g} / \mathrm{L})$ and elevated levels of lactate $(5.8 \mathrm{mmol} / \mathrm{L})$. Cyto-microbiological analysis found no CSF pleiocytosis (6 leukocytes $/ \mathrm{mm}^{3}$ ) and the absence of bacteria as determined by Gram staining.

The patient was admitted to the intensive care unit (ICU) with a diagnosis of purpura fulminans with uncertain meningitis. During the following $12 \mathrm{~h}$, multiple organ dysfunction syndrome progressively appeared with the following features: disseminated intravascular coagulation (DIC) [elevated prothrombin time (PT) (26\%), elevated activated partial thromboplastin time (aPTT) (2.54), low fibrinogen $(1.4 \mathrm{~g} / \mathrm{L})$, thrombopenia $\left(62 \times 10^{9}\right.$ platelets $\left./ \mathrm{L}\right)$, elevated D-dimers $(>10.000 \mathrm{ng} / \mathrm{mL})$ and low factor $\mathrm{V}$ (21\%)]; severe hypotension resistant to $20 \mathrm{~mL} / \mathrm{kg}$ fluid resuscitation and requiring treatment with $0.4 \mu \mathrm{g} / \mathrm{kg} / \mathrm{min}$ norepinephrine; non-obstructive acute renal failure; acute lung injury with mild pulmonary oedema upon chest $\mathrm{X}$-ray and no cardiac failure upon the first echocardiographic examination (left-ventricular ejection fraction (LVEF) 70\%), requiring oxygen delivery through a mask up to $9 \mathrm{~L} / \mathrm{min}$ flow, and metabolic acidosis ( $\mathrm{pH} 7.28$, lactate $6.4 \mathrm{mmol} / \mathrm{L}$ ). In addition, plasma procalcitonin (PCT) levels were very high $(521 \mu \mathrm{g} / \mathrm{L})$. Encephalic computerised tomography (CT) scan and magnetic resonance imaging (MRI) ruled out the presence of a pharyngeal or cerebral abscess, cerebral thrombophlebitis, sinusitis, mastoiditis, and ethmoiditis. The patient was treated IV with $250 \mathrm{mg} /$ $\mathrm{kg} /$ day cefotaxime.

Neisseria meningitidis was first identified in the blood cultures after $15 \mathrm{~h}$, confirming the diagnosis of meningococcemia with purpura fulminans and shock. Numerous $N$. meningitidis colony-forming units were then identified in the CSF cultures $24 \mathrm{~h}$ after sampling. Furthermore, pathological examination of skin biopsies taken from purpuric areas revealed thrombosis of all the dermal capillaries associated with the presence of cocci in several vessels (Fig. 1). The N. meningitidis strain isolated belonged to serogroup $\mathrm{C}$ and was fully susceptible to penicillin (minimum inhibitory concentrations for penicillin, amoxicillin and ceftriaxone of 0.047, 0.125, and $<0.016 \mathrm{mg} / \mathrm{L}$, respectively). The patient had never been vaccinated against meningococcus. Human immunodeficiency virus serology was negative.

Organ failure improved by the second day after admission. Oxygen delivery was decreased to $4 \mathrm{~L} / \mathrm{min}$ and the norepinephrine infusion rate reduced to $0.2 \mu \mathrm{g} / \mathrm{kg} / \mathrm{min}$. Creatinine serum levels decreased to $2.1 \mathrm{mg} / \mathrm{dL}$ (estimated clearance of $40 \mathrm{~mL} / \mathrm{min}$ ), haemostasis parameters improved (PT $42 \%$, aPTT 1.85 , fibrinogen $4.5 \mathrm{~g} / \mathrm{L}$ ), and the blood lactate concentration decreased to $5.7 \mathrm{mmol} / \mathrm{L}$ (Fig. 1). A recurrence of hypotension, however, led to the diagnosis of 


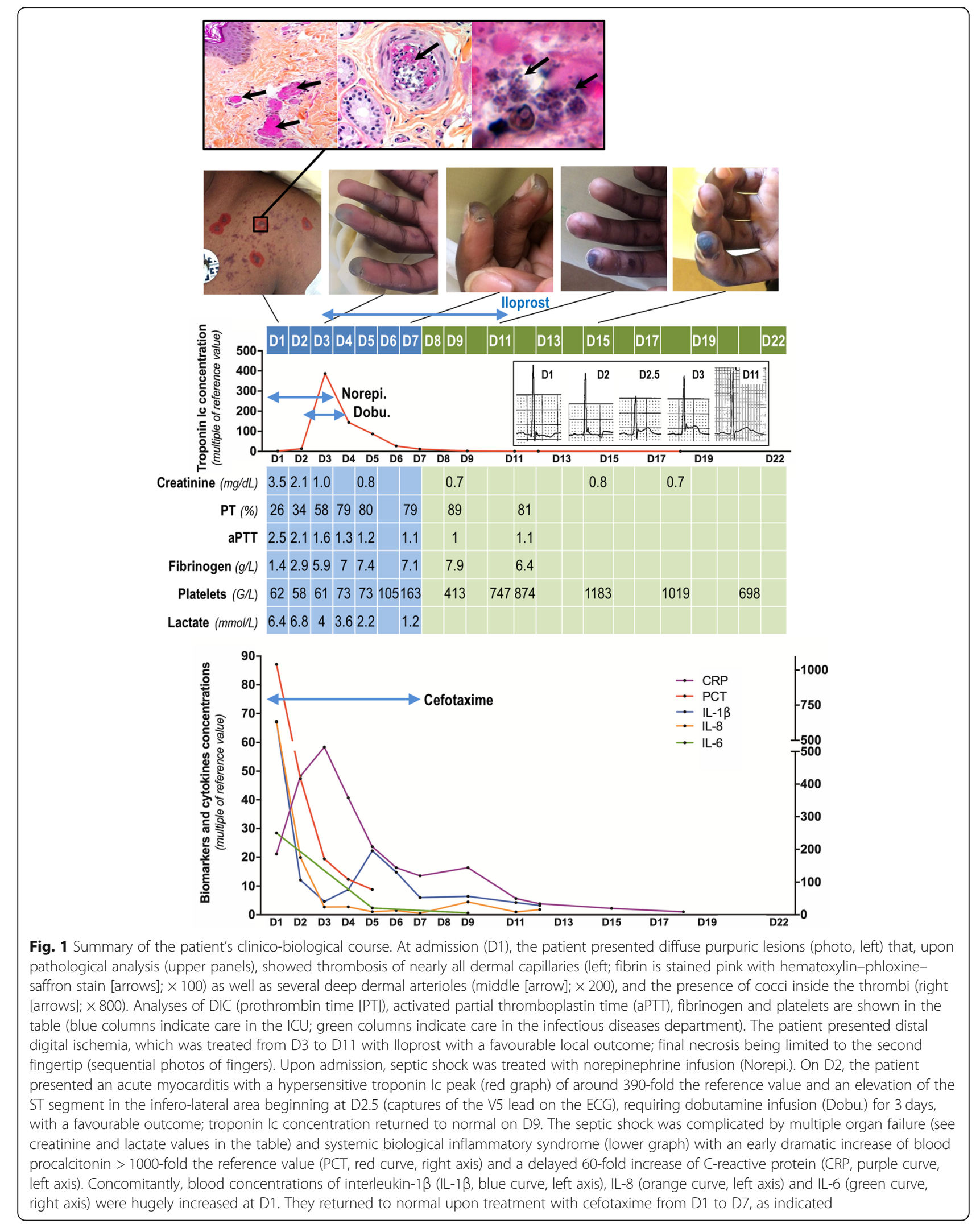


acute myocarditis upon echocardiography, with decreased LVEF (40\%), diffuse left-ventricular hypokinesia, and low left-ventricular output $\left(2.4 \mathrm{~L} / \mathrm{min} / \mathrm{m}^{2}\right.$ with aortic velocitytime integral of $13.5 \mathrm{~cm}$ ). An electrocardiogram revealed an elevation of the ST segment in the infero-lateral area (Fig. 1). Blood levels of hypersensitive troponin Ic increased rapidly to reach a peak of $>13,000 \mathrm{ng} / \mathrm{L} 44 \mathrm{~h}$ after admission, and then decreased and normalized within 14 days. Hypotension was corrected by IV infusion of $10 \mu \mathrm{g} / \mathrm{kg} / \mathrm{min}$ dobutamine for $36 \mathrm{~h}$ until left-ventricular function was completely restored. A myocardial MRI scan performed at day 8 showed no residual segmental or global left-ventricular dysfunction, no perfusion defect, and no abnormal contrast enhancement after injection of gadolinium.

All organ dysfunctions resolved during further treatment in the ICU. Nevertheless, distal hypoperfusion remained, in particular, in the distal phalanges of both hands. To avoid necrosis of the fingers, the patient was treated for 9 days with systemic (Iloprost $2 \mathrm{ng} / \mathrm{kg} / \mathrm{min}$ by continuous IV) and local (Trinitrine patches $10 \mathrm{mg} /$ day applied to all distal phalanges) vasodilators. Dermal necrosis occurred only on the pulp of the left index finger, bilaterally on the pulp of the big toes, the left ear lobe and the foreskin. Cefotaxime was discontinued after 7 days. The patient was transferred to the infectious disease ward 7 days after admission into the ICU. He was circumcised at day 12 to treat the foreskin necrosis and was finally discharged from the hospital at day 22 after favourable evolution of all necrotic lesions.

\section{Discussion and conclusions}

This patient suffered from purpura fulminans complicated by DIC and multiple organ dysfunction syndrome, including severe acute myocarditis. Three aspects of this case make it instructive.

First, although typical clinical signs of meningitis were observed and numerous $N$. meningitidis bacteria were isolated from CSF cultures, the biochemical and cytological analyses of the CSF did not identify meningeal inflammation. This discrepancy has been described previously in $0.5-12 \%$ of cases of paediatric meningitis [4-6]. It is rare, however, in non-neutropenic and non-immunocompromised adults [7-9]; in most reported cases, adults suffering from meningitis with normal initial CSF analysis had an incomplete clinical presentation with, in particular, a lack of neck stiffness $[5,10,11]$. Furthermore, in most reported cases where pleiocytosis was absent, CSF analysis showed moderate hyperproteinorachia or hypoglycorachia [8], neither of which was seen in our case. In several cases where no bacteria were found in cultures of the CSF sampled by a first lumbar puncture, subsequent lumbar puncture later found high pleiocytosis and the presence of bacteria [8], suggesting that the first CSF sample was taken too early to observe the meningeal inflammatory response. This early sampling might explain the lack of bio-cytological indicators of inflammation in the CSF of our patient; however, culture of the CSF sample taken at the first lumbar puncture found a high inoculum of $N$. meningitis bacteria. Thus, our case appears to be an intermediate form of meningococcal disease between purulent meningitis (indicated by the typical clinical signs and CSF microbiological cultures) and paucisymptomatic meningeal inoculation from fulminant meningococcal septicaemia (indicated by the cyto-biochemical CSF analysis). Despite the lack of cyto-biochemical signs of meningeal inflammation, the elevated level of CSF lactate seen in this case was a warning sign of bacterial meningitis. A previous prospective cohort of patients with meningitis and negative CSF upon Gram staining reported that CSF lactate concentration was the best marker to discriminate bacterial from aseptic meningitis [12]. A CSF lactate concentration $>3.8 \mathrm{mmol} / \mathrm{L}$ was $94 \%$ sensitive, $97 \%$ specific, and had $82 \%$ positive and $99 \%$ negative predictive values to indicate the bacterial origin of the meningitis [12]. This finding was confirmed by two meta-analyses that found that CSF lactate concentration was the best diagnostic tool to discriminate bacterial from aseptic or viral meningitis, particularly when lumbar puncture was performed prior to antibiotic administration [13, 14]. Thus, despite the absence of pleiocytosis, hypoglycorachia, or hyperproteinorachia, our patient's CSF lactate concentration of $5.8 \mathrm{mmol} / \mathrm{L}$ led us to maintain empirical cefotaxime administration at $250 \mathrm{mg} / \mathrm{kg} /$ day. When considered together with the previous reports mentioned above, the current case should encourage physicians not to discard a diagnosis of acute bacterial meningitis on the basis of a normal CSF cell count, and/or Gram staining but to be attentive to CSF lactate values in cases of suspected bacterial meningitis, as recommended recently $[9,15]$.

Second, this patient presented a delayed acute myocardial dysfunction, which occurred $36 \mathrm{~h}$ after admission to hospital. An acute coronary syndrome due to the occlusion of a coronary artery was ruled out based on clinical and echocardiographic data and was definitively disproved by cardiac MRI. This acute myocardial dysfunction might then be explained by at least three other pathophysiological causes: septic shock, meningococcal-related myocarditis and DIC-related myocardial injury. Sepsis-related myocardial dysfunction occurs in about one third of septic patients and, in 30\% of cases, it occurs after the first $24 \mathrm{~h}$ of septic shock management, consistent with this case [16]. The pathophysiology of septic cardiomyopathy is complex and still a subject of debate, but a direct effect of inflammatory cytokines, myocardial inflammatory oedema, increased oxidative stress, and decreased expression of adrenergic receptors likely contribute to the malfunction of the myocardium [17]. Notably, 
IL-1 $\beta$, which was dramatically elevated in this case (Fig. 1), is reported to cause a concentration-dependent depression of myocardial cell contractility [18]. Meningococcal-related acute myocarditis is probably an underdiagnosed complication of meningococcal disease. Indeed, myocarditis has been reported in $30 \%$ of adult patients suffering from the most severe forms of invasive meningococcal disease requiring ICU admission [19]. In these cases, left-ventricular dysfunction may be due to direct bacterial injury of the myocardium and to the meningococci-induced inflammatory response $[20$, 21], which may be cytotoxic for the myocardium [22]. In addition, meningococcal disease is specifically associated with high production of IL-6, as we observed in this case (Fig. 1), causing cytokine-mediated myocardial depression $[23,24]$. Thus, systemic meningococcal spread and the associated IL- 6 overexpression may have contributed to the myocardial dysfunction observed in our patient. Finally, it has been reported that the extent of myocardial dysfunction and levels of troponin correlate with the severity of the meningococcal coagulopathy in paediatric ICU patients [25]. As this patient presented severe DIC, it is also possible that distal myocardial microthrombi contributed to the cardiac dysfunction.

The third informative aspect of this case is the use of vasodilators to reduce the extent of skin necrosis. Distal ischemia and necrosis are common complications of the purpura fulminans coagulopathy $[3,26]$ and severe vasoconstriction and intravascular thrombosis have previously been associated with poor prognosis in meningococcal shock [27]. Several pathophysiological factors contribute to peripheral vasoconstriction, capillary thrombosis and skin necrosis during meningococcal disease: deficiency in the production of prostacyclin (a potent inhibitor of platelet aggregation and powerful vasodilator) by the vascular endothelium [28], enhanced endothelial activation and production of leucocyte adhesion molecules [29], and increased systemic plasminogen activator inhibitor-1 (PAI-1) levels contributing to reduce fibrinolysis and promote DIC [30]. Iloprost is an analogue of prostacyclin whose pharmacological effects include vasodilation of arterioles and venules, inhibition of platelet activation, and induction of fibrinolysis. Thus, its use may contribute to the treatment of several pathophysiological processes underlying skin necrosis. No prospective studies have assessed its efficacy to reduce the extent of meningococcal-related skin necrosis, however. Only two old paediatric case reports of prostacyclin use to this end are available [31, 32]. In the current case, we administered Iloprost according to the protocol used for Raynaud's Syndrome and in association with local treatment with trinitrine patches. Tolerance was good and there was no need to reintroduce catecholamine. Local evolution was favourable without recourse to surgery except to treat a hyperalgic ulcerative necrotic lesion of the foreskin. Although the efficacy of Iloprost for the treatment of skin necrosis cannot be assessed from this one case, our observations are encouraging for future studies that would evaluate the potential efficacy of systemic and/or local vasodilator treatments in preventing and/or improving the evolution of skin necrosis.

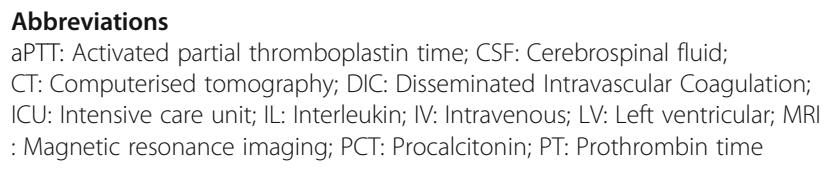

\section{Acknowledgements}

The authors thank Carol Featherstone from Plume Scientific Communication Services SAS (Toulouse, France) for editing the manuscript.

The authors also many thank Dr. Sophie Bailleul from the biochemistry laboratory of Tenon Hospital for preliminary biochemical analysis of the case, and Dr. Sebastian Tavolaro from the radiology department of Tenon Hospital for having reviewed and validated the cardiac MRI results.

\section{Funding}

This case report has not been funded by any external source.

\section{Availability of data and materials}

Data sharing is not applicable to this article as no datasets were generated or analysed during the current study.

\section{Authors' contributions}

M.H-S. performed biochemical analyses and drafted the manuscript. N.D., C.V., O.G., G.P., P.S. and M.F. participated in patient care and revised the manuscript. M.B. performed cytokine dosages and revised the manuscript. M.G. participated in patient care, collected the data and drafted the manuscript. All authors have read and approved the final manuscript.

Ethics approval and consent to participate Not applicable.

\section{Consent for publication}

The patient gave his written consent for the publication of the clinical details and photographs showed in this case report.

\section{Competing interests}

The authors declare that they have no competing interests related to this article.

\section{Publisher's Note}

Springer Nature remains neutral with regard to jurisdictional claims in published maps and institutional affiliations.

\footnotetext{
Author details

${ }^{1}$ Assistance Publique-Hôpitaux de Paris (APHP), Tenon University Hospital, Biochemistry Laboratory, 4 Rue de la Chine, 75020 Paris, France. ${ }^{2}$ Assistance Publique-Hôpitaux de Paris (APHP), Tenon University Hospital, Medico-Surgical Intensive Care Unit, 4 Rue de la Chine, Paris 75020, France. ${ }^{3}$ Assistance Publique-Hôpitaux de Paris (APHP), Groupe Hospitalo-Universitaire Paris Est, Bacteriology Laboratory, 184 Rue du Faubourg Saint-Antoine, Paris 75012, France. ${ }^{4}$ Assistance Publique-Hôpitaux de Paris (APHP), Tenon University Hospital, Infectious Diseases Department, 4 Rue de la Chine, Paris 75020, France. ${ }^{5}$ Assistance Publique-Hôpitaux de Paris (APHP), Tenon University Hospital, Anatomopathology Laboratory, 4 Rue de la Chine, Paris 75020, France. ${ }^{6}$ Assistance Publique-Hôpitaux de Paris (APHP), Tenon University Hospital, Dermatology Department, 4 Rue de la Chine, Paris 75020, France. ${ }^{7}$ Sorbonne University School of Medicine, Paris VI, Paris, France. ${ }^{8}$ INSERM UMR-S 938, Saint-Antoine Research Center, Sorbonne Université, Paris, France. ${ }^{9}$ Assistance Publiuqe-Hôpitaux de Paris (APHP), Tenon University Hospital, Anaesthesiology and Intensive Care Medicine Department, 4 Rue de la Chine -, 75020 Paris, France.
} 
Received: 2 October 2018 Accepted: 1 March 2019

Published online: 12 March 2019

\section{References}

1. Brandtzaeg P, Ovstebøo R, Kierulf P. Compartmentalization of lipopolysaccharide production correlates with clinical presentation in meningococcal disease. J Infect Dis. 1992;166:650-2.

2. Rosenstein NE, Perkins BA, Stephens DS, Popovic T, Hughes JM. Meningococcal disease. N Engl J Med. 2001;344:1378-88.

3. Stephens DS, Greenwood B, Brandtzaeg P. Epidemic meningitis, meningococcaemia, and Neisseria meningitidis. Lancet Lond Engl. 2007; 369:2196-210

4. Polk DB, Steele RW. Bacterial meningitis presenting with normal cerebrospinal fluid. Pediatr Infect Dis J. 1987;6:1040-2.

5. Coll MT, Uriz MS, Pineda V, Fontanals D, Bella F, Nava JM, et al. Meningococcal meningitis with "normal" cerebrospinal fluid. J Inf Secur. 1994;29:289-94.

6. Troendle M, Willis D. Fulminant bacterial meningitis due to Neisseria meningitidis with no pleocytosis on lumbar puncture. Am J Emerg Med 2017:35:198.e1-2.

7. Huynh W, Lahoria R, Beran RG, Cordato D. Meningococcal meningitis and a negative cerebrospinal fluid: case report and its medicolegal implications. Emerg Med Australas EMA. 2007;19:553-5.

8. Hase R, Hosokawa N, Yaegashi M, Muranaka K. Bacterial meningitis in the absence of cerebrospinal fluid pleocytosis: a case report and review of the literature. Can J Infect Dis Med Microbiol J Can Mal Infect Microbiol Medicale. 2014;25:249-51.

9. van de Beek D, Cabellos C, Dzupova O, Esposito S, Klein M, Kloek AT, et al. ESCMID guideline: diagnosis and treatment of acute bacterial meningitis. Clin Microbiol Infect Off Publ Eur Soc Clin Microbiol Infect Dis. 2016; 22(Suppl 3):S37-62.

10. Onorato IM, Wormser GP, Nicholas P. "Normal" CSF in bacterial meningitis. JAMA. 1980;244:1469-71.

11. Lessing MP, Bowler IC. Normocellular cerebrospinal fluid in meningococcal meningitis. J Inf Secur. 1995;31:248-9.

12. Viallon A, Desseigne N, Marjollet O, Birynczyk A, Belin M, Guyomarch S, et al. Meningitis in adult patients with a negative direct cerebrospinal fluid examination: value of cytochemical markers for differential diagnosis. Crit Care Lond Engl. 2011;15:R136.

13. Huy NT, Thao NTH, Diep DTN, Kikuchi M, Zamora J, Hirayama K. Cerebrospinal fluid lactate concentration to distinguish bacterial from aseptic meningitis: a systemic review and meta-analysis. Crit Care Lond Engl. 2010;14:R240.

14. Sakushima K, Hayashino Y, Kawaguchi T, Jackson JL, Fukuhara S. Diagnostic accuracy of cerebrospinal fluid lactate for differentiating bacterial meningitis from aseptic meningitis: a meta-analysis. J Inf Secur. 2011;62:255-62.

15. Tunkel AR, Hasbun R, Bhimraj A, Byers K, Kaplan SL, Michael Scheld W, et al. 2017 Infectious Diseases Society of America's clinical practice guidelines for healthcare-associated Ventriculitis and meningitis. Clin Infect Dis Off Publ Infect Dis Soc Am. 2017.

16. Boissier F, Razazi K, Seemann A, Bedet A, Thille AW, de Prost N, et al. Left ventricular systolic dysfunction during septic shock: the role of loading conditions. Intensive Care Med. 2017:43:633-42.

17. Ehrman RR, Sullivan AN, Favot MJ, Sherwin RL, Reynolds CA, Abidov A, et al. Pathophysiology, echocardiographic evaluation, biomarker findings, and prognostic implications of septic cardiomyopathy: a review of the literature. Crit Care Lond Engl. 2018;22:112.

18. Kumar A, Thota V, Dee L, Olson J, Uretz E, Parillo J. Tumor necrosis factor alpha and interleukin 1 beta are responsible for in vitro myocardial cell depression induced by human septic shock serum. J Exp Med. 1996;183: 949-58.

19. Madelaine T, Cour M, Bohé J, Floccard B, Duperret S, Hernu R, et al. Invasive meningococcal disease-induced myocarditis in critically ill adult patients: initial presentation and long-term outcome. Intensive Care Med. 2017;43: 279-81.

20. Monsalve F, Rucabado L, Salvador A, Bonastre J, Cuñat J, Ruano M. Myocardial depression in septic shock caused by meningococcal infection. Crit Care Med. 1984;12:1021-3.

21. Guarner J, Greer PW, Whitney A, Shieh W-J, Fischer M, White EH, et al. Pathogenesis and diagnosis of human meningococcal disease using immunohistochemical and PCR assays. Am J Clin Pathol. 2004;122:754-64.
22. Thiru Y, Pathan N, Bignall S, Habibi P, Levin M. A myocardial cytotoxic process is involved in the cardiac dysfunction of meningococcal septic shock. Crit Care Med. 2000;28:2979-83.

23. Pathan N, Hemingway CA, Alizadeh AA, Stephens AC, Boldrick JC, Oragui EE, et al. Role of interleukin 6 in myocardial dysfunction of meningococcal septic shock. Lancet Lond Engl. 2004;363:203-9.

24. Makwana N, Baines PB. Myocardial dysfunction in meningococcal septic shock. Curr Opin Crit Care. 2005;11:418-23.

25. Briassoulis G, Narlioglou M, Zavras N, Hatzis T. Myocardial injury in meningococcus-induced purpura fulminans in children. Intensive Care Med. 2001:27:1073-82

26. Betrosian AP, Berlet T, Agarwal B. Purpura fulminans in sepsis. Am J Med Sci. 2006:332:339-45.

27. Flaegstad T, Kaaresen PI, Stokland T, Gutteberg T. Factors associated with fatal outcome in childhood meningococcal disease. Acta Paediatr Oslo Nor 1992. 1995:84:1137-42

28. Heyderman RS, Klein NJ, Shennan GI, Levin M. Deficiency of prostacyclin production in meningococcal shock. Arch Dis Child. 1991;66:1296-9.

29. Fassbender K, Schminke U, Ries S, Ragoschke A, Kischka U, Fatar M, et al. Endothelial-derived adhesion molecules in bacterial meningitis: association to cytokine release and intrathecal leukocyte-recruitment. J Neuroimmunol. 1997:74:130-4.

30. Brandtzaeg $P$, Joø GB, Brusletto B, Kierulf P. Plasminogen activator inhibitor 1 and 2, alpha-2-antiplasmin, plasminogen, and endotoxin levels in systemic meningococcal disease. Thromb Res. 1990;57:271-8.

31. Stewart FJ, McClure BG, Mayne E. Successful treatment of neonatal purpura fulminans with epoprostenol. J R Soc Med. 1991;84:623-4.

32. Winrow AP. Successful treatment of neonatal purpura fulminans with epoprostenol. J R Soc Med. 1992;85:245.

\section{Ready to submit your research? Choose BMC and benefit from:}

- fast, convenient online submission

- thorough peer review by experienced researchers in your field

- rapid publication on acceptance

- support for research data, including large and complex data types

- gold Open Access which fosters wider collaboration and increased citations

- maximum visibility for your research: over $100 \mathrm{M}$ website views per year

At BMC, research is always in progress.

Learn more biomedcentral.com/submissions 